\title{
A partnership model to improve population health screening for noncommunicable conditions and their common risk factors, Qazvin, Islamic Republic of Iran
}

\author{
S. Alikhani ${ }^{1}$ and B. Damari ${ }^{2}$
}

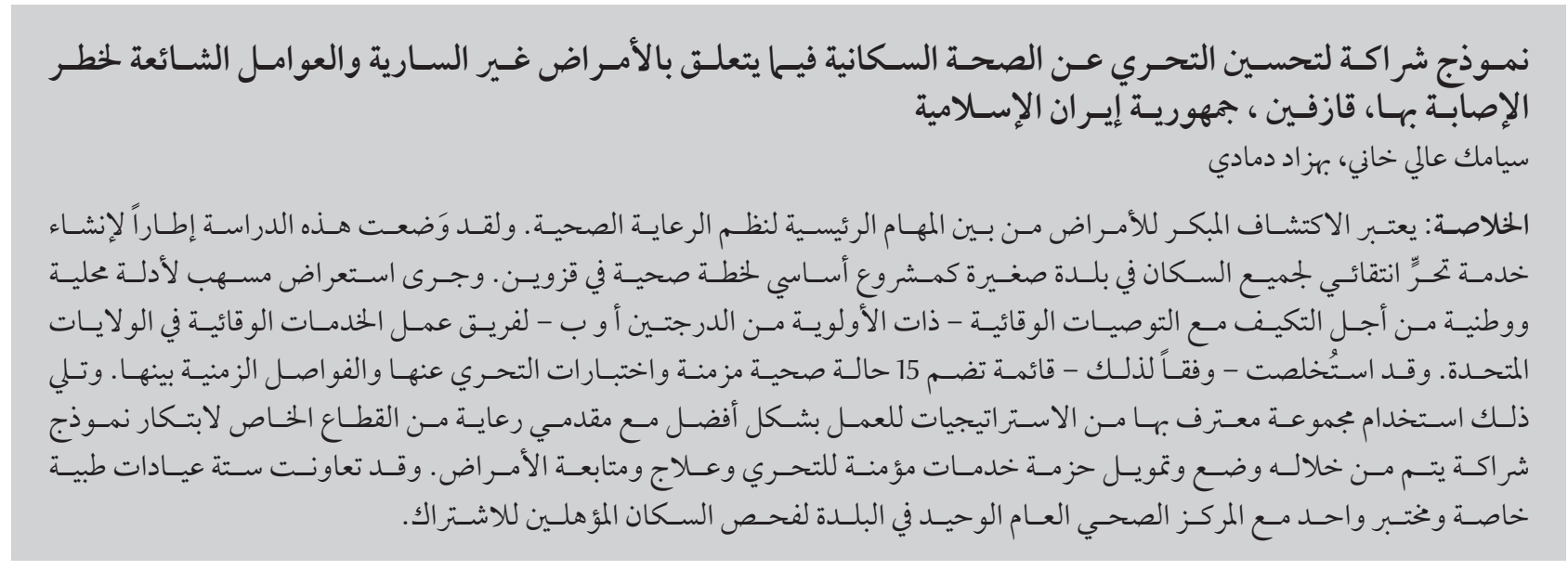

ABSTRACT Early findings and management of health conditions are among the key functions of health care systems. We developed a partnership framework to establish an extended primary health care-based selective screening service for the entire population of a small town as a key project of Qazvin Health Plan, Qazvin, Islamic Republic of Iran. Eight scientific associations and a diverse technical taskforce extensively reviewed evidence to adapt the grade A and B preventive recommendations of the American Preventive Service Taskforce. A list of 15 priority health conditions was identified and screening protocols were developed accordingly. Then strategies for working with private sector providers for better health care were applied to form our partnership model through which we ensured provision of screening services in 3 areas: service provision, quality and costs. Six private medical offices and a laboratory cooperated with the public health centre of the town to screen eligible residents. Preliminary analysis of the results suggests that the framework has successfully engaged private care providers.

Modèle de partenariat pour améliorer le dépistage des maladies non transmissibles et leurs facteurs de risque courants dans la population, Qasvin (République islamique d'Iran)

RÉSUMÉ Le dépistage précoce des maladies est l'une des fonctions centrales des systèmes de soins de santé. La présente étude a mis au point un cadre afin d'établir un service de dépistage sélectif pour l'ensemble de la population d'une petite ville comme projet clé du Plan sanitaire de Qasvin. Les données locales et nationales ont été examinées en détail afin d'adapter les recommandations de prévention prioritaires des niveaux $\mathrm{A}$ et $\mathrm{B}$ du US Preventive Services Taskforce (Groupe de travail sur les services de prévention des États-Unis).Une liste de 15 affections chroniques, les tests de dépistage associés et leurs intervalles ont été établis en fonction. Par la suite, un ensemble de stratégies éprouvées visant à mieux collaborer avec les prestataires de soins privés a été utilisé pour concevoir un modèle de partenariat grâce auquel des services couverts par une assurance pour le dépistage, le suivi et de prise en charge des maladies seraient créés et financés. Six cabinets médicaux privés et un laboratoire ont coopéré avec le seul centre de santé publique de la ville pour sélectionner les résidents éligibles. L'analyse préliminaire des résultats laisse penser que le cadre a permis d'impliquer les prestataires de soins privés

${ }^{7}$ Association of International Medical Graduates of British Columbia, Vancouver, Canada. ${ }^{2}$ National Institute of Health Research, Tehran, Islamic Republic of Iran (Correspondence to B. Damari: bdamari@gmail.com).

Received: 16/11/15; accepted: 20/07/16 


\section{Introduction}

Screening programmes are launched to detect a disease or a risk factor that can potentially cause manageable health conditions (1); however, a screening activity should never be thought of as a service itself. Screening is always a part of a wider strategy that may include definitive diagnosis, health promotion and disease prevention or control. Implementation of community-based screening is an equitable approach to addressing population health because it identifies and addresses the needs of less-affluent people and fulfils the principles of primary health care (2). There are few noncommunicable disease programmes in the Islamic Republic of Iran that include a community-based screening component.

The Iranian primary health care system of was developed more than 3 decades ago, initially to respond to a variety of health problems that were mostly contagious in nature. It basically covered rural populations and inhabitants of small towns (3). During the past few decades, the progressive trend towards urbanization and its consequences has advocated for some reforms in the primary health care system including efforts to expand services for the residents of larger cities and to address emerging health priorities (4). Integration of new programmes to tackle chronic diseases has been one of those measures because noncommunicable diseases and accidents are the major factors affecting the burden of disease in the Islamic Republic of Iran. In 2011 there were about 4 million Iranian adults (11.4\%) with diabetes, which represented a $35 \%$ increase over 7 years (5). In the same year, the prevalence of hypertension, obesity, low physical activity, low fruit and vegetable consumption and hypercholesterolaemia among adults was $19.0 \%, 16.8 \%$, $44.9 \%, 22.0 \%$ and $27.9 \%$ respectively (6). These are common risk factors for ischaemic heart disease, which imposes the highest disease burden on Iranians, and for some other prevalent chronic conditions which also impose a high burden. Comparing with other countries in the Region, the Iranian health system is still not ranked as highly effective when considering burden of disease indicators such as disability adjusted life years (DALYs), a fact that shows it has not been able to effectively respond to noncommunicable diseases in particular (7). Hypertension and diabetes prevention and control programmes are the only 2 nationwide noncommunicable disease intervention programmes which include a population-based screening component. Despite their integration into the Iranian primary health care system, only about half the people affected are aware of their health condition $(8,9)$, a fact that challenges both the quality and the extent of the screening component of the 2 programmes. In addition, a significant number of those who are diagnosed with diabetes and hypertension are not medically controlled, a sign of inadequate or ineffective care after disease detection $(10,11)$.

The Qazvin Health Plan, an ongoing initiative to improve health policy and planning practices at the provincial level, targeted noncommunicable diseases as the priority health condition of the population through an initiative that aims to find a solution for 2 important problems, identifying diseases and/ or risk factors that could change the trend of noncommunicable diseases in the province, and strengthening the local primary health care system in Mohammadyeh, a small town with about 40000 residents, by introducing a best practices in public-private partnership model to the system to handle screening and care protocols properly and effectively.

\section{Methods}

\section{Study design and setting}

The framework we devised to prioritize noncommunicable diseases and risk factors for screening and care using a convenient, evidence-based method was developed by reviewing the relevant literature and expert opinion. The public-private partnership reform we set up to improve primary health care services in an uraban setting was adapted from a known method (12). Therefore, our initiative included 2 steps that are discussed here. The implementation report is the subject of a separate paper to be published later.

\section{Step 1: Identifying target conditions for screening}

This step consists of a literature review and consensus-building using an expert panel. We reviewed evaluation reports of past and current community-based screening programmes in the Iranian health system and the 2012 international recommendations of the American Preventive Service Taskforce (13). Our purpose was to provide a list of diseases or risks that are high priority for screening in the primary health care system, i.e. conditions graded A and B (strongly recommended and recommended).

We then established a panel of experts to rate the final table of target preventive measures. We purposely recruited experts for this part of our study (14) to select "the most knowledgeable individuals in the relevant field" (15). Three senior clinicians in the field of internal medicine, gynaecology and paediatrics, a professor of epidemiology and an associate professor in health economy were recruited. We devised a questionnaire to collect experts' opinion at this stage on 5 inclusion criteria of screening: validity, reliability, yield, cost and follow-up services (16). Efforts like this usually rely on both available evidence and collective judgements, and are based on the experts' definition of what forms an effective practice. Past 
performance of similar initiatives can also be used as a sound basis for our purposes. We used the RAND-UCLA appropriateness method as our approach for systematically combining evidence and the collective judgment of experts (17). This includes a comprehensive literature review to assess the available evidence on the target subject to elaborate a framework, followed by collating the experts' opinions.

The experts were requested to rate each of the criteria for the recommended tests on a 5-point scale $(1=$ strongly agree, 5 = strongly disagree). For each condition, only one clinician of the related field was asked to comment. Points for each question were summed up to give a simple sum score for each condition, which could be in the range $5-25$. We considered an appropriateness score of 5 as the cut-off point in acceptance of each screening measure, i.e. any screening measure with score $\leq 4$ for each criterion was selected.

\section{Step 2: Designing the public- private partnership model}

This step comprised a literature review and community mobilization component. At this stage we reviewed all available relevant clinical practice guidelines as well as 2 evaluation reports of the national diabetes and hypertension screening programmes to outline what we require to amend in the infrastructure and procedures of the existing services.

A set of recommended strategies for working with private sector providerswas used to set up our screening plan (12). Through this approach, we targeted 3 areas:

- increase service provision,

- improve quality of services,

- control costs.
We used specific strategies to address policy-makers, care providers and the community for each target area. A stakeholder analysis led us to form a steering committee in which we finalized and endorsed the strategies. The committee compried 11 executives, officers and experts from relevant sectors in Qazvin province.

\section{Results}

We identified 21 diseases/risks at grade A or B in the Preventive Service Taskforce recommendations that were addressed by at least 1 technical programme of the health system (13). The summary the of experts' opinions on these conditions is shown in Table 1 .

The final screening interventions approved by the expert panel were restricted to 6 conditions. The experts agreed on sex, age, gold standard and

\begin{tabular}{|c|c|c|c|c|c|}
\hline \multirow[t]{2}{*}{ Disease or risk factor to be screened } & \multicolumn{5}{|c|}{$\begin{array}{c}\text { Appropriateness score } \\
(\mathbf{1}=\text { most appropriate, } 5 \text { = least appropriate) }\end{array}$} \\
\hline & Validity & Reliability & Yield & Cost & Follow-up \\
\hline Osteoporosis & 1 & 1 & 2 & 4 & 3 \\
\hline Iron deficiency anaemia & 1 & 1 & 1 & 4 & 5 \\
\hline Hypertension & 1 & 1 & 1 & 1 & 1 \\
\hline Breast cancer & 1 & 1 & 1 & 1 & 1 \\
\hline Cervical cancer & 1 & 2 & 2 & 1 & 2 \\
\hline Prostate cancer & 1 & 2 & 3 & 4 & 3 \\
\hline Colon cancer & 1 & 1 & 1 & 1 & 1 \\
\hline Depression & 2 & 2 & 1 & 2 & 3 \\
\hline Diabetes & 1 & 1 & 1 & 1 & 1 \\
\hline Hypercholesterolaemia & 1 & 1 & 1 & 1 & 1 \\
\hline Neonatal impaired hearing & 1 & 1 & 1 & 2 & 1 \\
\hline Hepatitis B & 1 & 1 & 2 & 1 & 4 \\
\hline Obesity & 1 & 1 & 1 & 1 & 1 \\
\hline Syphilis & 1 & 1 & 2 & 2 & 3 \\
\hline Aneurism of abdominal aorta & 1 & 1 & 2 & 3 & 4 \\
\hline Alcohol abuse & 2 & 2 & 1 & 1 & 3 \\
\hline Tobacco use & 1 & 1 & 1 & 1 & 1 \\
\hline Gonorrhoea & 1 & 1 & 2 & 1 & 2 \\
\hline Chlamydia infection & 2 & 2 & 2 & 1 & 3 \\
\hline HIV/AIDS & 1 & 2 & 3 & 3 & 3 \\
\hline Asymptomatic bacteriuria & 1 & 1 & 3 & 2 & 2 \\
\hline
\end{tabular}




\begin{tabular}{|c|c|c|c|c|c|}
\hline Health condition & Age (years) & Grade $^{a}$ & Sex & Reference test & Recommended testing interval \\
\hline Diabetes & $18-65$ & B & Both & Fasting plasma glucose & Every 3 years \\
\hline Breast cancer & $45-65$ & B & Female & Mammography & Every 2 years \\
\hline Colon cancer & $50-65$ & A & Both & Faecal occult blood & Annually \\
\hline \multirow{4}{*}{$\begin{array}{l}\text { High blood } \\
\text { cholesterol }\end{array}$} & $20-35$ & B & Male & \multirow[t]{4}{*}{ Blood total cholesterol } & \multirow[t]{4}{*}{ Every 5 years } \\
\hline & $35-65$ & A & & & \\
\hline & $20-45$ & B & Female & & \\
\hline & $45-65$ & A & & & \\
\hline Smoking & $15-65$ & A & Both & Question & 1st visit \\
\hline Hypertension & $18-65$ & A & Both & Sphygmomanometer & $\begin{array}{l}\text { Every } 2 \text { years for those with } \\
\text { normal blood pressure; } \\
\text { annually for those with } \\
\text { hypertension }\end{array}$ \\
\hline Obesity & $6-65$ & B & Both & Body mass index & 1st visit \\
\hline
\end{tabular}

a US Preventive Service Taskforce recommendations (12).

Grade A: The USPSTF found good evidence that the service improves important health outcomes and concludes that benefits substantially outweigh harms. Grade B: The USPSTF found at least fair evidence that the service improves important health outcomes and concludes that benefits outweigh harm.

test intervals for each item. Table 2 provides brief information about the target conditions.

The research team developed a clinical practice guideline for each health condition in the list through review of all available national clinical guidelines as well as evaluation reports on national screening programmes for diabetes and hypertension. These guidelines were adapted to the local context and needs to make the screening process as feasible as possible.

Extensive negotiations with provincial stakeholders resulted in some changes in regulations and services that were required to provide a sound and appropriate prototype. The local health authority revised all of the routine forms and processes to comply with the new guidelines and mandates.

- Our efforts to negotiate with a variety of stakeholders resulted in the following achievements, listed under 3 strategies we used to encourage the highest participation of private care providers.

- Increase coverage of products and services with a public health benefit which are affordable for target groups:
- three major public health insurance providers accepted to cover the costs of screening tests;

- subsidized referral and follow-up services provided by Qazvin University of Medical Sciences;

- six physicians who had private medical offices in different zones of the city agreed to cooperate with the initiative to reduce copayments;

- the only private medical laboratory in the city joined the efforts to reduce copayments for laboratory tests;

- media campaign designed and arranged, including local radio and television broadcasts, brochures, posters and billboards to inform citizens about the project;

- clients covered by the main charity organization, Emdad Relief Organization, were exempted from all screening costs.

- Limit harmful practices and improve technical quality of care:

- strict auditing protocols developed to supervise both public and private providers using checklists based on clinical guidelines and standard operational procedures;
- training events designed for contractors from private medical offices and public health workers to introduce our protocol for screening, referral and follow-up;

- screening processes, costs and goals were clearly described through brochures and distributed door-to-door.

- Control treatment costs to users:

- all tariffs for diagnostic tests, visits and counselling were clearly estimated and approved by the provincial medical council and introduced to the private providers during orientation and recruitment sessions; insurance companies, Emdad ReliefOrganization and the health authority of the town developed a cooperation mechanism to control payments;

- the optimum number of visits for each private doctor and the partner laboratory was estimated; they are paid through insurance companies.

\section{Discussion}

The Qazvin Comprehensive Health Plan of was a provincial initiative begun 
consequent to a community health assessment and through building political commitment at the level of Governor General of the province. It targeted health as the pivotal element of sustainable development and tried to exemplify the Health in All Policies (18). During the development of the plan, the steering committee was convinced of the fundamental need to focus on areas of priority to amalgamate all concerns and resources. Therefore, while the advisory team began working on health sector reform, they had to rely on the current burden of disease information to identify health care priorities.

Among all causes of mortality and morbidity, noncommunicable diseases and their common risk factors impose the maximum burden on the health and economy of Iranians (19). In response, 2 nationwide programmes for hypertension and diabetes have been integrated into the primary health care system since the 1990s (20); however, there are doubts whether they could be considered promising initiatives $(10,11)$. Therefore, it is important to analyse these programmes when trying to establish a promising screening intervention, which we attempted before developing our model.

While about $60 \%$ of the population resides in urban areas of the country, it is currently estimated that only about $30 \%$ of the adult urban population have been screened for hypertension and diabetes and referred for treatment when indicated (21). The situation is worse for the rural population. However, diabetes control is more effective where rural health workers provide health care services. This could be attributed to the rather insufficient follow-up and lifestyle modification training provided by care providers, mainly physicians, in the cities (22).

On the other hand, we should consider how some of the 9 basic requirements for screening (23) are systematically ignored by the diabetes and hypertension screening programmes, especially in regard to knowledge about the prevalence of the 2 conditions, facilities needed, acceptability and equity. The 2 programmes were initiated when there was not enough evidence on the distribution of the conditions in the country. The first national surveillance survey that was able to quantify and map the prevalence of the conditions was conducted in 2005 , some years after the screening programmes had been launched nationwide (24). This lack of clear epidemiologic knowledge has resulted in an inappropriate estimation of the infrastructure the country needed to undertake screenings and consequent follow-up and management efforts. Also, as the public were not educated about diabetes and hypertension, they neither accepted screening nor what should be done after cases are identified. Poor control results among those who receive treatment can be a sign of this lack of public knowledge and acceptability. Finally, the obvious difference between the prevalence of diabetes and hypertension among men and women, and urban versus rural areas was not addressed properly by the Iranian health care system, which undermined equitable access to health services.

Through this study, we have tried to use all the lessons we learnt from the past and combine them with evidence-based practices to prepare our new model for screening of chronic health conditions, a model that is highly responsive to the WHO Package of essential noncommunicable (PEN) disease interventions for primary health care in low-resource settings initiative (25). Thus, the design is based on primary health care to ensure equitable access to health services, only a set of feasible, evidence-based interventions were selected to be included in the model and all three levels of health care are involved to ensure those who are found to have a problem will receive appropriate services as well. However, we acknowledge that access to specialized care and some medical technologies is still a problem that needs to be responded to thoroughly using the field results. Reimbursement of travel costs may be one solution.

Although we believe that our experience could improve the screening and care for noncommunicable diseases and risk factors at the primary care level, we also acknowledge that our efforts may fail to prepare secondary care because of the existing disparities we face in healthcare provision thoroughout the province at this level. We are also aware that the sustainability of the partnership model wehave proposed could be diminished over time by the shift of political commitment of those key stakeholders who have supported the partnership framework, either financially or technically. On the other hand, the pilot Family Physician Programme (26), the only infrastructural reform that could challenge the results of our initiative, is now limited to rural areas and cities with less than 20000 inhabitants. However, an evaluation of this programme suggests considering the role of the private sector in areas where the public primary health care system is challenged by it (27). This could increase the importance of building a partnership between private and public players.

\section{Acknowledgements}

Qazvin University of Medical Sciences provided financial and technical support for our project. We thank Dr Aliakbar Zeinaloo, the then Chancellor of the University, Dr Majid Rajabi and Saeid Jafari, who coordinated our project at the provincial level. We also acknowledge consultations provided by the national advisory team, particularly the late Dr Kamel Shadpour, Dr Abbas Vosough Moghaddam and Dr Hossein Salarianzadeh.

Funding: None.

Competing interests: None declared. 


\section{References}

1. Herman CR, Gill HK, Eng J, Fajardo LL. Screening for preclinical disease: test and disease characteristics. AJR Am J Roentgenol. 2002 Oct;179(4):825-31. PMID:12239019

2. Braveman PA, Tarimo F. Screening in primary health care. Geneva: World Health Organization; 1994.

3. Malekafzali H. Primary health care in the rural area of the Islamic Republic of Iran. Iranian J Publ Health. 2009;38(Suppl. 1):69-70

4. Imanieh MH, Sadati AK, Moghadami M, Hemmati A. Introducing the Urban Community Health Center $(\mathrm{UCHC}$ ) as a nascent local model: Will it be a linchpin in the health sector reform in Iran? Int J Health Policy Manag. 201504 02;4(5):331-2. PMID:25905489

5. Esteghamati A, Etemad K, Koohpayehzadeh J, Abbasi M, Meysamie A, Noshad S, Asgari F, et al. Trends in the prevalence of diabetes and impaired fasting glucose in association with obesity in Iran: 2005-2011. Diabetes Res Clin Pract. 2014;103(2):319-27. PMID:24447808

6. Iran STEPS Survey 2011, fact sheet. Tehran: Ministry of Health and Medical Education; 2015.

7. Shahrzad S, Forouzanfar MH, Sepanlou SG, Dicker D, Naghavi $\mathrm{P}$, Pourmalek F, et al. Population health and burden of disease profile of Iran among 20 countries in the region: from Afghanistan to Qatar and Lebanon. Archives of Iranian Medicine. 2014;17(5): 336-42. PMID:24784862

8. Esteghamati A, Gouya MM, Abbasi M, Delavari A, Alikhani S, Alaedini F, et al. Prevalence of diabetes and impaired fasting glucose in the adult population of Iran: National Survey of Risk Factors for Non-Communicable Diseases of Iran. Diabetes Care. 2008 Jan;31(1):96-8. PMID:17921357

9. Esteghamati A, Abbasi M, Alikhani S, Gouya MM, Delavari A, Shishehbor $\mathrm{MH}$, et al. Prevalence, awareness, treatment, and risk factors associated with hypertension in the Iranian population: The National Survey of Risk Factors for Non-communicable Diseases of Iran. Am J Hypertens. 2008 Jun;21(6):620-6. PMID:18451810

10. Ebrahimi M, Mansournia MA, Haghdoost AA, Abazari A, Alaeddini F, Mirzazadeh A, et al. Social disparities in prevalence, treatment and control of hypertension in Iran: second National Surveillance of Risk Factors of Noncommunicable Diseases. J Hypertens. 2010;28(8):1620-9. PMID:20647858

11. Delavari A, Alikhani S, Nili S, Birjandi RH, Birjandi F. Quality of care of diabetes mellitus type II patients in Iran. Arch Iran Med. 2009;12(5):492-5. PMID:19722773

12. Smith E, Brugha R, Zwi A. Working with private sector providers for better health care: an introductory guide. London: London School of Hygiene and Tropical Medicine and Options Consultancy Services; 2001. (http://www.who.int/management/partnerships/private/privatesectorguide.pdf?ua=1, accessed 5 October 2016)

13. The guide to clinical preventive services 2012: Recommendations of the U.S. Preventive Services Task Force. Rockville, Maryland: US Preventive Service Taskforce; 2012 (http://www. uspreventiveservicestaskforce.org/Home/GetFileByID/236, accessed 5 October 2016).

14. Onwuegbuzie AJ, Leech NL. Sampling designs in qualitative research: making the sampling process more public. Qual Rep. 2007 Jun;12(2):238-54.
15. Polkinghorne DE. Language and meaning: data collection in qualitative research. J Couns Psychol. 2005;52:137-45.

16. Wilson JMG, Jungner G. Principles and practice of screening for disease. Geneva: World Health Organization; 1968 (Public Health Papers 34) (http://apps.who.int/iris/bitstream/10665/37650/17/WHO_PHP_34.pdf, accessed 5 October 2016)

17. The RAND/UCLA Appropriateness method user's manual. Santa Monica, California: The RAND Corporation; 2001 (http://www.rand.org/pubs/monograph_reports/MR1269. html, accessed 5 October 2016).

18. Lin V, Jones C, Wang S, Baris E. 2014. Health in All policies as a strategic policy response to NCDs. Health, Nutrition, and Population (HNP) discussion paper. Washington, DC: World Bank; 2014.

19. Shahraz S, Forouzanfar MH, Sepanlou SG, Dicker D, Naghavi $P$, Pourmalek F, et al. Population health and burden of disease profile of Iran among 20 countries in the region: from Afghanistan to Qatar and Lebanon. Arch Iran Med. 2014 May;17(5):336-42. PMID:24784862

20. Azizi F, Guoya MM, Vazirian P, Dolatshati P, Habbibian S. Screening for type 2 diabetes in the Iranian national programme: a preliminary report. East Mediterr Health J. 2003;9(5-6):1122-7. PMID:16450546

21. Lankarani KB, Alavian SM, Peymani P. Health in the Islamic Republic of Iran, challenges and progresses. Med J Islam Repub Iran. 2013;27(1):42-9. PMID:23479501

22. Farzadfar F, Murray CJ, Gakidou E, Bossert T, Namdaritabar H, Alikhani $\mathrm{S}$, et al. Effectiveness of diabetes and hypertension management by rural primary health-care workers (Behvarz workers) in Iran: a nationally representative observational study. Lancet. 2012 Jan 7;379(9810):47-54. PMID:22169105

23. Strong K, Wald N, Miller A, Alwan A. Current concepts in screening for noncommunicable disease: World Health Organization Consultation Group report on methodology of noncommunicable disease screening. J Med Screen. 2005;12:12-9. PMID:15825234

24. Alikhani S, Delavari A, Alaedini F, Kelishadi R, Rohbani S, Safaei A. A province-based surveillance system for the risk factors of non-communicable diseases: A prototype for integration of risk factor surveillance into primary healthcare systems of developing countries. Public Health. 2009 May;123(5):358-64. PMID:19386334

25. Package of essential noncommunicable (PEN) disease interventions for primary health care in low-resource settings. Geneva: World Health Organization; 2010 (http://www.who. $\mathrm{int} / \mathrm{nmh} /$ publications/essential_ncd_interventions_Ir_settings.pdf, accessed 5 October 2016).

26. Lankarani KB, Alavian SM, Haghdoost A. Family physicians in Iran: success despite challenges. Lancet. 2010;376(9752):15401. PMID:21056761

27. Takiana A, Doshmangirc L, Rashidiand A. Implementing family physician programme in rural Iran: exploring the role of an existing primary health care network. Fam Pract. 2013 Oct;30(5):551-9. PMID:23788202. 